\title{
Forebrain mechanisms in the relief of fear: The role of the lateral septum
}

\author{
EARL THOMAS \\ Bryn Mawr College, Bryn Mawr, Pennsylvania
}

\begin{abstract}
The septal region is a central link in a major forebrain inhibitory system. This paper presents evidence suggesting that an important function of septal inhibition is the suppression of aversive emotional states. Support for such a proposition is derived from a confluence of three kinds of evidence: (1) evidence that electrical stimulation of the septal region has the ability to inhibit aversive states; (2) evidence that lesions of the septal region reduce or abolish the ability of environmental stimuli to inhibit aversion; (3) and evidence that activity of cells in the lateral septum is increased in the presence of stimuli which inhibit aversion. It is concluded that the dynamic activity of the septal region and related areas is essential for the control and guidance of aversively motivated behavior.
\end{abstract}

The septal region of the forebrain, especially the lateral septum, is part of an extensive system of forebrain structures concerned with what might be called general inhibition (Delgado, 1975). The activity of these structures appears to promote widespread inhibition in a number of other brain areas. In addition to the septal region, structures that may be classified as generally inhibitory include portions of the basal ganglia, including the caudate nucleus, and portions of the limbic system or structures related to the limbic system, including the hippocampus, the region of the diagonal band of Broca, and the preoptic area. What ties these areas together functionally is that electrical stimulation produces behavioral arrest, or what Hess (1954) termed "adynamia" - a lack of volitional behavior or lack of behavior initiation. Such arrest has been shown for the preoptic area by Hess (1954), for the septal area by Kaada (1951), for the diagonal band by Sterman and Clemente (1962), and for the caudate nucleus by Buchwald, Wyers, Lauprecht, and Heuser (1961).

Whether these structures constitute parts of a unitary inhibitory system is not clear, although this seems somewhat unlikely. Specific behavioral functions have been ascribed to several of these structures. Thus, Sterman and Clemente (1962) suggested that the diagonal band area is related to sleep, and earlier Hess (1954) had suggested a similar function for the preoptic area. Buchwald et al. (1961) suggested a motor inhibitory function for the caudate nucleus, and Kaada (1951) suggested a similar function for the septum and subcallosal area. Thus, the evidence suggests that the functions of forebrain inhibition are several and include motor, attentional, and emotional inhibition. These functions undoubtedly interact at some

A major portion of this paper was written while the author was a visiting scientist at the Weizmann Institute of Science, Rehovot, Israel. The author would like to thank Elna Yadin for her many contributions to the paper. Requests for reprints should be sent to Earl Thomas, Department of Psychology, Bryn Mawr College, Bryn Mawr, PA 19010. final common path to behavior; however, the nature of this interaction is very poorly understood.

The purpose of this paper is to reexamine the inhibitory role of one basal forebrain region, the septum. Considerable evidence now points to an important role of the septohippocampal system in a variety of learning and $\operatorname{cog}$ nitive functions. Several of these functions have been reviewed by Thompson (1976), Olton (1978), and O'Keefe and Nadel (1978), to name just a few. If the hippocampus is importantly involved in cognitive and memorial functions, as now seems evident, then the septal region is placed in a highly strategic position to relate cognitions and memories to their emotional contexts, and ultimately, to translate memories and cognitions into motivated behavior. Consistent with such a role, the septal region appears to be at the interface of two important neural networks.

First, it appears to be part of a septohippocampal feedback circuit in which all fields of the hippocampus proper (Ammon's horn), as well as the subiculum, project via the fimbria-fornix to the lateral septum. There is a massive set of connections from the lateral to the medial septum (Swanson \& Cowan, 1979), which in turn projects back via the fimbria-fornix to all fields of the hippocampus. It should be pointed out that while the anatomy of the circuit suggests a feedback loop, there is no clear evidence at the functional level that the circuit has such a role.

Second, the septal region serves as an important link between the hippocampus and the septal-preoptichypothalamic-midbrain axis (Nauta, 1958, 1982). Indeed, as Swanson and Cowan (1979) pointed out, the lateral septum appears to be the only subcortical connection from the hippocampus proper. One is tempted to speculate that the hippocampus-septum-hippocampus circuit is part of a cognitive information processing loop, whereas the septal-midbrain connection is the link with the emotionalmotivational system. 
The basic premise advanced here is that the role of the septum, particularly the lateral septum, in this link is to inhibit aversive emotional states. That is, I believe that the evidence can support the idea that the lateral septal region mediates relief from fear or anxiety and may be seen as an important structure in providing goal direction for aversively motivated behavior reinforced by relief from fear or anxiety.

In putting forward a hypothesis related to concepts such as fear, anxiety, and relief from fear, it is important to specify precisely what these concepts mean within the experimental context, since these terms as generally applied are somewhat vague and ill-defined. For the purposes of this paper, the terms fear and anxiety will refer to central aversive states elicited by conditioned or unconditioned aversive stimuli or by direct electrical stimulation of aversive brain regions. Delgado, Roberts, and Miller (1954) described the great similarity of these sources of aversive emotional states. The properties they have in common include (1) the ability to motivate avoidance behavior, (2) the ability to suppress behavior upon which the presentation of such stimuli has been made contingent, and (3) the ability to suppress ongoing operant behavior in the conditioned emotional response (CER) paradigm of Estes and Skinner (1941).

It should be pointed out that no claim for the theoretical unity of these properties is being made here. Indeed, there is some reason to believe that the three paradigms, in addition to tapping some common properties of conditioned aversive stimuli, have some very important differences. Perhaps the most striking example is the fact that anxiolytic drugs have their predominant effects upon only one of these paradigms, namely behavior inhibited by punishment. In spite of such differences, I believe the conditioning paradigm to be the best model we have for the etiology and properties of human fear or anxiety.

Relief from fear may be defined in terms of the properties of a conditioned stimulus (CS) that has been established as a conditioned inhibitor of fear by being negatively correlated with an aversive unconditioned stimulus (US). Such a stimulus acquires the ability to counteract the aversive properties of a fear CS when presented in compound with the fear stimulus. This is typically seen either as a diminution in the amplitude of aversive conditioned responses or as the retardation of the acquisition of aversive conditioning (Rescorla, 1969a). Such a stimulus also acquires the ability to serve as a positive reinforcer when presented in an aversive context. An animal in a state of fear will work to produce a stimulus that has been established as a conditioned inhibitor of fear (Morris, 1975; Rescorla, 1969b; Weisman \& Litner, 1972).

Given this working definition of relief from fear, a number of observations from work in our laboratory, using a variety of procedures, provide support for the fearrelieving function of the lateral septum. These observations may be summarized as follows: (1) Electrical stimulation of the lateral septal region has the ability to relieve fear. (2) The ability of environmental stimuli to relieve fear is diminished or abolished as a result of lesions of the lateral septal area. (3) Increased activity of lateral septal cells is recorded in the presence of environmental stimuli that have fear-relieving properties.

In the following sections I examine in more detail the experimental evidence underlying these generalizations.

\section{Stimulation Experiments}

The literature on electrical stimulation bears very importantly upon the hypothesis that the lateral septum is involved in the relief of fear or anxiety. In general, stimulation of the septal region produces arrest or inhibition of ongoing behavior (Kaada, 1951). It seems clear, however, that among the classes of behavior that are inhibited by lateral septal stimulation is the class that could best be described as emotional.

Siegel and Skog (1970), for instance, showed that lateral septal stimulation suppressed certain forms of brainstimulated aggression in cats. Brayley and Albert (1977) found that lateral, but not medial, septal stimulation in rats suppressed aggression produced by lesions of the ventromedial nucleus of the hypothalamus. Beagley (1972) noticed that lateral septal stimulation resulted in a general calming effect on cats; that is, behavior indicating distress, such as mewing or vigorous struggling against a restraint, was greatly suppressed by septal stimulation. Incidentally, the termination of septal stimulation was almost invariably followed by a rebound increase in distressed vocalization and struggling.

Indirect evidence for the fear-relief hypothesis of septal functioning may be obtained from experiments on intracranial self-stimulation (ICSS) and related experiments. The septal region is a well-known self-stimulation site in the rat. Indeed, this was the site stimulated by Olds and Milner (1954) in their initial demonstration of ICSS. Rolls (1975) summarized a number of differences between rhinencephalic (e.g., septal) ICSS and ICSS in other regions of the brain, such as the medial forebrain bundle (MFB), differences that are consistent with a fear-relieving role of the septum. Thus MFB stimulation is accompanied by arousal, hyperactivity, and high rates of response, whereas septal stimulation is accompanied by lowered arousal, hypoactivity, reduced rates of response over the session, and even sleep. Consistent with this dichotomy is the finding that MFB self-stimulation is accompanied by cardiac acceleration (Perez-Cruet, Black, \& Brady, 1963), whereas lateral septal self-stimulation is accompanied by cardiac deceleration (Malmo, 1961, 1965). In a series of experiments on the effects of rewarding stimulation on aversive states, Routtenberg and Olds (1963) compared MFB stimulation with septal stimulation. They found that noncontingent hypothalamic stimulation increased escape responses to dorsal midbrain stimulation, whereas noncontingent septal stimulation decreased escape responses. In a later extension of these studies, Routtenberg and Olds (1966) found that both electrical stimulation and chemical stimulation of the dorsal midbrain suppressed self-stimulation of the hypothalamus, but not 
of the septal area. They suggested that septal stimulation decreases some activational components of the aversive stimulation, whereas hypothalamic stimulation increases them.

Septal stimulation, in addition to somatomotor effects, has autonomic effects that are consistent with a fearrelieving role of the lateral septum. Stimulation of the septal region has been shown to decrease blood pressure (Covian, Antunes-Rodriguez, \& O'Flaherty, 1964) and to produce cardiac deceleration (Holdstock, 1967). There is also evidence that septal stimulation inhibits pituitaryadrenal activity in rats (Taylor, Branch, Cassaday, \& Turner, 1973). Beagley (1972) found that lateral septal stimulation in the cat resulted not only in general somatomotor inhibition, but also in general visceromotor inhibition. The galvanic skin response elicited by stimulation of a number of regions of the brain-including the lateral and posterior hypothalamus, central gray, midbrain reticular formation, and amygdala-was appreciably suppressed by concomitant electrical stimulation of the lateral septum.

The fact that lateral septal stimulation yields both somatomotor and visceromotor suppression, as well as a general calming effect, seems to indicate that the lateral septum has an important emotion-suppressing function. However, these data alone are insufficient to support such a conclusion. Valenstein (1973) provided a trenchant critique of premature interpretations concerning the emotional functions of inhibitory brain stimulation. Valenstein pointed out that such stimulation may have purely motor effects, and that apparent reductions in emotionality seen as a result of such stimulation may represent nothing more than confusion on the part of the animal. The vast majority of the literature cited above-although perhaps suggesting that the lateral septum plays an emotion-inhibiting role--is largely inferential, indirect, and subject to the more parsimonious response-inhibition interpretation. Recently, the research in our laboratory has been directed at searching for definitive ways to separate the possible fear or anxiety inhibitory effects of septal function from its motor inhibitory effects, and if possible to characterize the dynamics of the fear-relieving functions of the lateral septum.

It is clear that, solely on the basis of gross behavioral observations, it is difficult to distinguish between a motorinhibiting effect and an aversion-inhibiting effect of septal stimulation. There is, however, one way to distinguish between these two possibilities. Stimulation that reduces emotion should have goal-directing properties that will be lacking in stimulation whose effect is purely somatomotor. That is, brain stimulation that can effectively reduce an aversive state should be rewarding when the animal is in an aversive state or is subjected to aversive stimulation.

In the course of our work at Bryn Mawr with septal stimulation in cats, it became apparent that the cat might be the ideal preparation for determining whether aversion confers reinforcing properties upon septal stimulation. In our studies, as well as in that of Wilkinson and Peele
(1963), stimulation of the lateral septal region of the cat, in contrast with the rat, typically did not support ICSS. Nevertheless, as I have pointed out, such stimulation does dramatically suppress several aspects of emotional expression. If the reduction in emotional expression reflects a genuine reduction in emotional state, then the animal should learn a response in order to obtain such stimulation when it is subjected to some form of aversion.

In the first experiment we attempted with cats (Thomas \& Evans, 1983, Experiment 1), the source of aversion was electrical stimulation of the hypothalamus; we had previously determined that such stimulation reinforced escape and avoidance behavior. The design of the experiment may be conceptualized as a quasi escape-avoidance paradigm in which the animal could not escape or avoid hypothalamic stimulation, but could mitigate its effects by presenting itself with concomitant lateral septal stimulation. The hypothalamic stimulation was administered to the animal for $5 \mathrm{sec}$, independent of the animal's response. However, if the animal performed an instrumental response (for some animals, a pole press; for others, a jump onto a platform), it would receive septal stimulation, which would remain on and coterminate with the hypothalamic stimulation.

Each of the 4 animals we tested under these conditions acquired the response that yielded septal stimulation. The terminal performance level was about $80 \%$ responding. Given this result, it was important to rule out the possibility that the apparent acquisition of the response was due merely to changes in response topography resulting from chronic hypothalamic stimulation, or to increasing activational effects of hypothalamic stimulation, perhaps due to sensitization. Thus, after acquisition, 2 of the animals were subjected to extinction in which hypothalamic stimulation continued but septal stimulation was no longer available. Both animals showed typical extinction curves, their terminal performance being close to zero.

Another important control in this kind of experiment is a control for the specificity of the hypothalamic stimulation. Does such stimulation have to be aversive, or will any activating hypothalamic stimulation support such learning? Fortunately, our paradigm provided for such a control. We had implanted electrodes in several sites. Stimulation of some of these sites elicited locomotor behavior that was not aversive, but appeared to observers to be simple voluntary locomotor behavior; such elicited behavior is thought to represent an extrapyramidal function of the hypothalamus (Hess, 1954). When we substituted stimulation of these sites for stimulation of the aversive sites, there was an immediate and complete cessation of the learned behavior. Stimulation of these sites did not confer reinforcing properties upon septal stimulation.

The results of this experiment were corroborated by a second experiment, using a somewhat different design (Thomas \& Evans, 1983, Experiment 2). In this case the aversive stimulation was cholinergic stimulation of the hypothalamus via the administration of crystalline carbachol. Baxter (1967) had shown intrahypothalamic ad- 
ministration of carbachol to be an extremely potent activator of emotional responses in the cat. The response to be learned was choice of the side of the chamber in which septal stimulation was administered. In spite of a number of parametric differences-in response requirements, nature of hypothalamic stimulation, and schedule of septal stimulation-all of the basic results of the first experiment were replicated in the second. The animals learned to choose the side of the chamber in which they received septal stimulation only when carbachol was administered to the hypothalamus; otherwise, they were completely indifferent to septal stimulation.

I would like to point out that all of the animals in both of these experiments were tested for ICSS, in a number of situations and under a variety of parameters. None of the animals self-stimulated, even after heroic attempts to shape such self-stimulation. This stands in marked contrast to the ease we have had in obtaining self-stimulation in cats with MFB sites (Dewald \& Thomas, 1976). In sum, these experiments strongly suggest that lateral septal stimulation in cats inhibits not only motor activity, but the emotional correlates of that activity as well. At least within the confines of these experiments, the animals would perform to obtain septal stimulation when, and only when, they were in an aversive state.

The data presented above suggest that lateral septal stimulation has the ability to reduce the aversiveness of electrical stimulation of the brain. But what about aversive CSs, which presumably represent the better model for what we normally term fear or anxiety? According to our conception, an aversive CS should also confer reinforcing properties upon septal stimulation. When we attempted to substitute an aversive CS for brain stimulation in cats in a paradigm identical to the one described above, we met with a singular lack of success. The problem was that after a few septal stimulations the animals became so relaxed that presentation of the CS was completely ineffective in eliciting any behavior in the animals. A number of other attempts with cats failed for the same reason; therefore, we decided to attack the problem in an indirect manner, using rats as subjects.

As I have pointed out, in rats there is considerable circumstantial evidence that septal ICSS, in contrast to MFB ICSS, may be associated with the relief of fear. Brady and Conrad (1960) demonstrated that rats self-stimulating in the septal region were resistant to the behavioral suppression typically seen in the CER paradigm. The septal self-stimulators persisted in their responding in the presence of the emotional CS, whereas animals performing for water reinforcement showed the usual suppression. It seemed to us that there were two plausible explanations for the persistence. One possibility was that there was extremely high incentive associated with ICSS, the explanation favored by Brady and Conrad. A second possibility was that the persistence was mediated by aversionreducing properties specific to septal ICSS. The CER literature subsequent to Brady and Conrad's experiment seemed to support the latter interpretation. The subsequent experiments tended to find that conditioned suppression could be obtained with ICSS. However, for the most part these experiments employed MFB sites of stimulation (e.g., McIntire, 1966; Merrill, 1976; Russell, 1975).

To test for differences in CER behavior between the two sites, we compared the susceptibility of lateral septal and MFB ICSS to conditioned suppression, using rats as subjects (Grauer \& Thomas, 1982). In brief, we superimposed on baseline ICSS a 30-sec light CS paired with a 1 -sec scrambled footshock. Because ICSS in the two brain regions yields markedly different rates, with MFB ICSS generating considerably higher rates, the CER was tested under varying current intensities at each site, to ensure that differences were not merely due to differences in baseline rates of responding. The major result of the experiment was that under optimal stimulating current, MFB sites, even though showing very high rates of baseline ICSS, were highly susceptible to conditioned suppression, whereas septal ICSS showed no evidence of conditioned suppression.

It seems unlikely that the differences between the two sites in susceptibility to conditioned suppression were due to differences in incentive value, since baseline rates of responding were higher in the MFB and since Hodos and Valenstein (1962) found that, under optimal stimulation animals with electrodes in both sites chose MFB over septal ICSS. Perhaps the best evidence comes from the 2 animals Grauer (1980) implanted with electrodes in both sites. These animals were trained to self-stimulate in each site and were tested for site preference prior to CER training and again after CER training. In agreement with the data of Hodos and Valenstein (1962), under baseline conditions, MFB ICSS was preferred virtually exclusively over septal ICSS. When the 2 animals were given a choice between MFB and septal self-stimulation under the CER condition, their behavior differed. One showed a complete reversal of site preference under the CER condition, now choosing septal stimulation virtually exclusively; moreover, this animal showed no conditioned suppression. The second animal seems to have solved the problem in a different way. During the preference test under the CER condition, this animal interspersed presses on the MFB lever with presses on the septal lever, a behavior never seen under the baseline condition. In this way the animal was able to obtain both kinds of stimulation, and under these conditions it showed resistance to conditioned suppression of both sources of ICSS.

In sum, the experiments described here, when taken in conjunction with the literature described in the previous section, lend strong support to the notion that one of the important functions of the general inhibition generated by lateral septal stimulation is the inhibition of aversive emotional states. Little is known about the effect of septal stimulation on positive hedonic states, but the picture here is somewhat murky. The one study that I am aware of that bears on this is by Miller and Mogenson (1971), who found that septal stimulation facilitated low rates of selfstimulation and inhibited high rates. Whether this result 
reflects a modulation of reward or a modulation of response rates is not clear at the moment, but certainly is worth further investigation.

\section{Septal Lesions and Fear Reduction}

If activation of the septum by electrical stimulation does inhibit fear, then it is a small step to the presumption that the ability of environmental stimuli to relieve fear may be mediated by the septal region. It might be expected, then, that septal lesions would abolish or diminish the fearrelieving properties of environmental stimuli. One important class of such stimuli are those referred to in the literature on animal learning as conditioned inhibitors of fear.

Rescorla (1969a) and Weisman and Litner (1972), among others, have shown that in an aversive Pavlovian conditioning situation, a stimulus explicitly unpaired with the US (a CS-) acquires inhibitory properties, and that such CSs have the ability to relieve fear. The fearrelieving properties of the CS are inferred from two kinds of observations: first, that superimposition of the CSupon ongoing avoidance behavior suppresses that avoidance behavior, and second, and perhaps more importantly, a CS- can serve as a positive reinforcer against a background of aversive stimulation. This second property is highly similar to the property of septal stimulation described in the preceding section, and was important in suggesting to us that the fear-relieving properties of inhibitory stimuli in Pavlovian aversive conditioning may be mediated by forebrain inhibitory areas, especially the lateral septum.

In an experiment using cats as subjects, Wagman (1972) demonstrated that the inhibitory effects of a $\mathrm{CS}-$ on avoidance behavior were abolished by septal lesions. In this experiment the animals received alternating sessions of Pavlovian discrimination training and one-way shuttlebox avoidance training. The CS for one-way avoidance was the opening of the door between the chambers. The CSs for Pavlovian conditioning were a light and a tone. Subsequent to conditioning, on a test day, avoidance was tested under three conditions. The opening of the door was preceded by a CS+ on one-third of the trials, by a CS- on one-third of the trials, and by no CS on one-third of the trials. Consistent with what is generally found in the literature, Wagman found that in nonlesioned animals one-way avoidance was significantly facilitated when the opening of the door was preceded by the Pavlovian CS + , and significantly suppressed when the opening of the door was preceded by the Pavlovian CS- . In the animals with septal lesions, the CS+ continued to facilitate avoidance but the inhibitory effect of the CS - was totally abolished.

Micco and Schwartz (1971) found a similar deficit in the acquisition of conditioned inhibition of fear in rats with hippocampal lesions. This suggests that both the septum and the hippocampus may be involved in this behavior, as they are in a variety of other behaviors.

That the deficit in the conditioned inhibition of fear is not merely a deficit in response inhibition in general may be seen by comparing this paradigm with another very important behavioral paradigm, the CER paradigm. In the CER paradigm, ongoing appetitively reinforced behavior is suppressed in the presence of a CS that has been paired with shock. The literature reveals considerable difficulty in obtaining deficits in the CER, both with septal lesions (Brady \& Nauta, 1953; Harvey, Jacobson, \& Hunt, 1961; Harvey, Lints, Jacobson, \& Hunt, 1965) and with hippocampal lesions (Kaplan, 1968; McGowan, Hankins, \& Garcia, 1972; Nadel, 1968). In the case of the septum, some recent experiments have shown positive effects (Dickinson, 1975; Feldon, Rawlins, \& Gray, 1982), but the magnitude of these effects seems modest in comparison to the complete abolition seen with a conditioned inhibitor of fear.

It should be noted that the conditioned-inhibition-of-fear paradigm and the CER paradigm are superficially similar, in that both involve suppression of a behavior by a CS. They differ radically, however, in their functional significance. The CER is a conditioned suppression of a positively reinforced operant and reflects an increase in fear, whereas the effect of a conditioned inhibitor of fear on aversively motivated behavior represents a decrease in fear. Although far from conclusive, the weight of the data suggests that the major effect of both septal and hippocampal lesions is on the conditioned inhibition of fear.

Perhaps a definitive experiment would be to look at the effects of septal lesions on conditioned inhibition of fear within the context of a CER paradigm. There is evidence in the literature (Hammond, 1966; Hammond \& Daniel, 1970) that in normal animals a conditioned inhibitor of fear, when superimposed upon a CS in the CER paradigm, diminishes the CER. Thus, a conditioned inhibitor of fear itself has the capacity to diminish the response inhibition seen in the CER paradigm. If the effect of a septal lesion is specific to the conditioned inhibition of fear, then the superimposition of a conditioned inhibitor upon a CS in the CER paradigm would result in greater suppression in septally lesioned animals than in normal animals. This would be contrary to what would be predicted by a deficit in general response inhibition. If the response-inhibition hypothesis is correct, the effect of a conditioned inhibitor of fear should be greater in septal animals, resulting in more release from response inhibition. The question of the behavioral specificity of septal lesions is a very important one and needs to be pursued further.

\section{Unit Recording}

The observation of a deficit in the conditioned inhibition of fear with septal lesions reinforced our view that the septum may be mediating the fear-inhibiting effects of environmental stimuli. We surmised, therefore, that if the septum is involved in the relief of fear, it might be possible to record unit activity in the region, correlated with such relief. It seemed reasonable as a first approximation that presentation of a conditioned inhibitor of fear might be reflected in increased unit activity in inhibitory regions such as the septum. Therefore, we carried out a series of multiple-unit recording experiments that were 
directed at determining the role of the septal region in fear relief (Thomas \& Yadin, 1980; Yadin \& Thomas, 1981).

In the first experiment (Thomas \& Yadin, 1980), rats were subjected to a Pavlovian differential conditioning paradigm, with light and tone as the CSs and footshock as the US. Increased multiple-unit activity above baseline activity was seen in the lateral septal region in the presence of the CS-. Moreover, the septal activity showed a significant growth function over the 28 sessions of training. On the other hand, multiple-unit activity was suppressed in the presence of the CS+. Increased multiple-unit activity was also seen at the termination of the shock US and at the termination of a tailpinch.

There is mounting evidence in the learning literature that the termination of an aversive stimulus is associated with the relief of fear (e.g., Denny, 1971; Konorski, 1972). Thus, in this experiment we had a variety of stimuli known to be associated with fear relief-the presentation of a conditioned inhibitor and the termination of two kinds of aversive stimulus, footshock and a tailpinch. The fact that unit activity in the lateral septum was seen in all of these cases is highly consistent with the hypothesis of a fear-relieving role for the lateral septum.

In a second series of experiments (Yadin \& Thomas, 1981), we attempted to rule out other possible interpretations for the increased septal activity observed in response to a CS-. One possibility was that perhaps the CS-, not being paired with the US, was merely habituating, and that septal activity reflected the habituation process. A second possibility was that septal activity represents all forms of Pavlovian "internal inhibition"-a function that would be consistent with its hypothesized role as a general behavior inhibitor, but inconsistent with a specific fear-relieving role.

We (Jadin \& Thomas, 1981) were able to rule out the first interpretation by repeating the original experiment of Thomas and Yadin (1980) with the addition of a "truly random" (Rescorla, 1967) control group. The stimuli randomly associated with the US yielded no change in septal activity over the 28 conditioning sessions. The results with the CS+ and CS- replicated our earlier findings (Yadin \& Thomas, 1981).

The possible role of the lateral septum in mediating all Pavlovian internal inhibition was assessed by repeating the Pavlovian conditioning procedure using an appetitive US (Yadin \& Thomas, 1981). The results of this experiment were virtually the mirror image of the results of the aversive conditioning experiments. Thus, in this case, the CS- did not yield increased septal firing, but rather suppressed septal activity. The CS+, on the other hand, was accompanied by an appreciable increase in septal activity. These data indicate that septal firing is not typical of all Pavlovian conditioned inhibition, but depends upon the hedonic properties of the US being employed.

A number of additional features of this experiment cast light upon the septum-fear-inhibition connection. For instance, baseline septal activity was very different in the animals receiving aversive conditioning and in the ran- dom control animals. In the conditioned animals the baseline activity remained unchanged over the 28 sessions, responding to the $\mathrm{CS}-$ being seen as an increase above the baseline rate. In the random control animals the baseline activity was considerably depressed after a number of presentations of the US. These data are consistent with the conditioning model of Wagner and Rescorla (1972), which predicts that cues of the chamber acquire aversive properties when there is no predictor of the shock US (in the random group), but when the CS does predict the occurrence of shock, then the cues of the chamber are not associated with fear. Thus in aversive contexts the ongoing activity of the lateral septum seems to be tightly linked to the moment-to-moment emotional state of the animal, with low rates reflecting high fear and high rates reflecting low fear.

Taken together, our recording experiments and the lesion data suggest that the conditioned inhibition of fear is an active neural process. In an earlier paper (Thomas, 1972), I argued that conditioned inhibitors must exert their effects by activating specific regions of the brain. The septal neurons studied here would seem to fit that bill, although it should be made clear that these most certainly are not the only neurons that may be expected to do so. For instance, Morrell and his associates (De ToledoMorrell, Hoeppner, \& Morrell, 1979; Morrell, Hoeppner, \& De Toledo-Morrell, 1983) found specific cells in the parastriate cortex in cats that were activated by a conditioned inhibitor of fear, indicating that cells mediating such inhibition probably occur at several levels of processing.

Another implication of our recording experiments is that unit activity in the lateral septum and elsewhere may reflect a hedonic similarity between a conditioned inhibitor in aversive conditioning and a conditioned excitor in appetitive conditioning. Considerable evidence in the learning literature suggests that conditioned excitors and inhibitors in opposite affective states are hedonically equivalent (for a review, see Dickinson \& Pearce, 1977). Segal, Disterhoft, and Olds (1972) found cells in the dentate gyrus of the hippocampal formation that seemed to reflect a similar hedonic equivalence. They found that cells that were inhibited by a "no-food" signal also were inhibited by a signal predicting shock. Indeed, there is a remarkable similarity between the findings of Segal et al. in the dentate gyrus and our findings in the lateral septum, although Segal et al. did not find cells that fired to a conditioned inhibitor of fear. This is probably because they did not carry conditioning far enough.

Whether the unit-activity changes observed in the lateral septum in response to a conditioned appetitive stimulus indicate a primary involvement of the septum in positive affect or indirectly reflect reciprocal innervation between positive- and negative-affect systems remains to be worked out. To my knowledge there is virtually no literature on the effect of septal lesions on Pavlovian appetitive conditioning. Septal lesions do appear to enhance rewarded behavior in some paradigms, such as the free-operant 
paradigm, and have variable effects in other paradigms, such as runway performance (see Gray \& McNaughton, 1983). There is at present no direct evidence linking these effects to the conditioning of affect, and most interpretations have concentrated on performance variables, such as changes in exploratory tendencies (see Gray, 1982, for a review).

It should be emphasized that the role of the septum as revealed by unit recording very likely presents a considerably more complicated picture than that presented here. Some of our more recent experiments have suggested that the septum is not homogeneous in the relation between unit firing and emotional states. Utilizing single-unit recording techniques, we found that the pattern of responding described above was restricted to the lateral septum (Thomas \& Yadin, 1983, 1987). The medial septum appears to yield unit responses to CSs that are generally the opposite of the responses seen in the lateral septum. These data have been reviewed elsewhere (Thomas \& Yadin, 1987), and I will not elaborate here. However, these data do provide evidence for a reciprocal relation between the medial and lateral septum that bears upon a theory of limbic system functioning proposed by Gray (1982), which is discussed below.

Finally, recent pharmacological work in our laboratory has provided a nice convergence of evidence bearing upon the fear-relieving role of the lateral septum. We found that in the awake chronically implanted rat, anxiolytic drugs tended to increase firing rates of lateral septal units, enhance the ability of a conditioned inhibitor of fear to increase firing rates, and block the unit-suppressing effect of a conditioned fear stimulus (Yadin, Thomas, \& Vaughan, 1986). This convergence of data suggests that the lateral septum may indeed be the final common path for the action of a variety of fear-reducing agents, such as conditioned inhibitors of fear and pharmacological inhibitors of fear.

\section{Is the Septohippocampal System Related to Anxiety or to Anxiety Relief?}

It may not have escaped the notice of readers familiar with the literature that much of what has been proposed here appears to be at variance with a theory of anxiety proposed by Gray (1982). According to Gray's model, the septohippocampal system comprises a behavioral inhibitory system, the activity of which mediates anxiety. The main evidence supporting Gray's theory is the similarity of the effects of anti-anxiety drugs and lesions of the septohippocampal system, especially in the release of behavior inhibited by punishment.

The apparent discrepancy between Gray's (1982) theory and the one proposed here highlights the importance of precision in identifying the role of brain structures in behavior and in characterizing the behavioral role of neural inhibition. Numerous studies have made clear that the septohippocampal system is not functionally homogeneous throughout. Lateral and medial septal lesions produce different results on a variety of measures, including be- havioral suppression (Feldon et al., 1982) and hippocampal theta activity (Rawlins, Feldon, \& Gray, 1979). There are also differences in the effects of stimulation of the lateral and medial septum. Stimulation of the lateral septum inhibits aggressive behavior, whereas stimulation of the medial septum does not (Brayley \& Albert, 1977). Lateral septal stimulation is accompanied by bradycardia, whereas medial septal stimulation is accompanied by an initial tachycardia followed by bradycardia (Malmo, 1965). The lateral and medial septum also differ in unit responding to CSs (Berger \& Thompson, 1978; Segal, 1973; Thomas \& Yadin, 1987).

Punished behavior is characterized by a combination of behavioral inhibition and high arousal. This observation has led Gray and others to equate behavioral inhibition and anxiety. On the basis of the evidence reviewed here, however, it appears that there is another behavior inhibition system, one associated with lowered arousal, the function of which is to mediate relief from fear or anxiety. The weight of the data reviewed here, especially the recording data from our laboratory, suggests that to the extent that the septal region participates in a septohippocampal anxiety system, it is the medial septum that does so, whereas the lateral septum is important as part of the fear-relief system.

\section{Conclusions and Directions for Future Research}

The control and modulation of anxiety appears to depend upon a complex interplay of structures involved in producing anxiety, such as the amygdala and perhaps the medial septum, and those involved in inhibiting anxiety, such as the lateral septum. It seems reasonable that the next step in research would be to examine the relationship between these systems in the guidance and control of aversively motivated behavior.

It is interesting that the functioning of these structures has parallel in drugs that affect anxiety. Drugs that are agonists for benzodiazepine (BZD) receptors in the brain serve to reduce fear or anxiety; they are referred to as anxiolytic drugs. There is also a class of compounds that are inverse agonists for BZD receptors. These compounds bind to BZD receptors but have an inverse effect upon the receptor-effector mechanism. These drugs appear to be able to cause fear or anxiety, and are therefore labeled anxiogenic. By analogy, I think it is fair to label those brain structures that promote anxiety as "anxiogenic" and those that inhibit anxiety as "anxiolytic." An understanding of the role of anxiogenic and anxiolytic structures is important in understanding the mechanism of action of anxiolytic and related compounds. This notion has been guiding current research in our laboratory into the action of anxiolytic and anxiogenic agents.

Most current models of the mechanism of action of anxiolytic drugs assume that the drugs act via the BZDGABA-Cl - ionophore complex in such a way as to enhance the inhibitory effects of GABA on putative anxiogenic structures such as the amygdala (e.g., Shibata, Katoaka, Yamashita, \& Ueki, 1986) or the raphe nuclei 
(e.g. Wise, Berger, \& Stein, 1972; see Soubrie, 1986, for a review). These models predict that lesions of anxiogenic structures should yield effects similar to those of anxiolytic drugs, and, for the most part, they do. However, these models also predict that such lesions should also diminish or abolish the anxiolytic action of drugs. In general, such lesions do not have such an effect. In fact, our own research (Yadin, Thomas, \& Strickland, 1987) suggests that amygdala lesions actually enhance the effects of anxiolytic drugs. One explanation for such an effect would be that at least part of the mechanism of anxiolytic drugs is to enhance the action of anxiolytic structures such as the lateral septum. Since the amygdala is reciprocally related to the lateral septum and related structures, an amygdala lesion might also be expected to enhance the anxiolytic action of these structures, and thereby to enhance the effect of anxiolytic drugs.

We are currently gathering evidence, based on lesioning studies and single-unit recording studies, for the interrelated roles of anxiogenic and anxiolytic structures in anxiclytic drugs' actions. The combination of behavioral, electrophysiological, and pharmacological data may provide a basis for a more complete understanding of the limbic mechanisms of emotion.

\section{REFERENCES}

BAXTER, B. L. (1967). Comparison of the behavioral effects of electrical or chemical stimulation applied at the same brain loci. Experimental Neurology, 20, 412-432.

BEAGLEY, G. A. (1972). Septal facilitation and inhibition of responses elicited from subcortical structures in the cat. Unpublished master's thesis, Bryn Mawr College, Bryn Mawr, PA.

Berger, T. W., \& Thompson, R. F. (1978). Neuronal plasticity in the limbic system during classical conditioning of rabbit nictitating membrane response: II. Septum and mammillary bodies. Brain Research, 156, 293-314.

Brady, J. V., \& Conrad, D. G. (1960). Some effects of limbic system self-stimulation upon conditioned emotional behavior. Journal of Comparative \& Physiological Psychology, 53, 128-137.

BradY, J. V., \& NaUTA, W. J. H. (1953). Subcortical mechanisms in emotional behavior: Affective changes following septal forebrain lesions in the albino rat. Journal of Comparative \& Physiological Psychology, 46, 339-346.

BraYleY, K. M., \& ALBERT, D. J. (1977). Suppression of VMH-lesioninduced reactivity and aggressiveness in the rat by stimulation of the lateral septum, but not medial septum or cingulate cortex. Journal of Comparative \& Physiological Psychology, 91, 290-299.

Buchwald, N. A., Wyers, E. J., Lauprecht, C. W., \& Heuser, G. (1961). The "caudate spindle": IV. A behavioral index of caudateinduced inhibition. Electroencephalography \& Clinical Neurophysiology, 13, 531-537.

Covian, M. R., Antunes-Rodriguez, J., \& O'FlaherTy, J. J. (1964). Effects of stimulation of the septal area upon blood pressure and respiration in the cat. Journal of Neurophysiology, 27, 394-407.

Delgado, J. M. R. (1975). Inhibitory systems and emotions. In L. Levi (Ed.), Emotions, their parameters and measurement (pp. 183-204). New York: Raven Press.

Delgado, J. M. R., RoberTs, W. W., \& Miller, N. E. (1954). Learning motivated by electrical stimulation of the brain. American Journal of Physiology, 179, 587-593.

Denny, M. R. (1971). Relaxation theory and experiments. In F. R. Brush (Ed.), Aversive conditioning and learning (pp. 235-295). New York: Academic Press.
De Toledo-Morrell, L., Hoeppner, T. J., \& Morrell, F. (1979). Conditioned inhibition: Selective response of single units. Science, 204, 528-530.

Dickinson, A. (1975). Suppressive and enhancing effect of footshock on food-reinforced operant responding following septal lesions in rats. Journal of Comparative \& Physiological Psychology, 88, 851-861.

Dickinson, A., \& PEARCE, J. M. (1977). Inhibitory interaction between appetitive and aversive stimuli. Psychological Bulletin, 84, 690-711. Estes, W. K., \& SKINNER, B. F. (1941). Some quantitative properties of anxiety. Journal of Experimental Psychology, 29, 390-400.

Feldon, J., Rawlins, J. N. P., \& GRay, J. A. (1982). Effects of lateral and medial septal lesions on response suppression maintained by response-contingent and response-independent shock. Physiological Psychology, 10, 145-152.

Grauer, E. (1980). [Differential effects of CER training on selfstimulation in septal and medial forebrain bundle sites in the same animal]. Unpublished raw data.

Grauer, E., \& Thomas, E. (1982). Conditioned suppression of medial forebrain bundle and septal intracranial self-stimulation in the rat: Evidence for a fear-relief mechanism of the septum. Journal of Comparative and Physiological Psychology, 96, 61-70.

GraY, J. A. (1982). The neuropsychology of anxiety: An enquiry into the functions of the septohippocampal system. Oxford: Oxford University Press.

Gray, J. A., \& McNaughton, N. (1983). Comparison between the behavioral effects of septal and hippocampal lesions: A review. Neuroscience \& Biobehavioral Reviews, 7, 119-188.

HAMmOND, L. J. (1966). Increased responding to CS - in differential CER. Psychonomic Science, 5, 337-338.

Hammond, L. J., \& DANIEL, R. (1970). Negative contingency discrimination: Differentiation by rats between safe and random stimuli. Journal of Comparative \& Physiological Psychology, 72, 486-491.

Harvey, J. A., Jacobson, L. E., \& Hunt, H. F. (1961). Long-term effects of lesions in the septal forebrain on acquisition and retention of conditioned fear. American Psychologist, 16, 449. (Abstract)

HARVEY, J. A., LinTS, C. E., JACoBson, L. E., \& HuNT, H. F. (1965). Effects of lesions in the septal area on conditioned fear and discriminated instrumental punishment in the albino rat. Journal of Comparative \& Physiological Psychology, 59, 37-48.

HEss, W. R. (1954). Diencephalon: Autonomic and extrapyramidal functions. New York: Grune \& Stratton.

Hodos, W., \& Valenstein, E. S. (1962). An evaluation of response rate as a measure of rewarding intracranial self-stimulation. Journal of Comparative \& Physiological Psychology, 55, 80-84.

HoLDSTOCK, T. L. (1967). Effects of septal stimulation in rats on heart rate, and galvanic skin response. Psychonomic Science, 9, 37-38.

KAADA, B. R. (1951). Somatomotor, autonomic and electrocorticographic responses to electrical stimulation of "rhinencephalic" and other structures in primates, cats, and dogs. Acta Physiologica Scandinavica, 24(Suppl. 83), 1-258.

KaplaN, J. (1968). Approach and inhibition reactions in rats after bilateral hippocampal damage. Joumal of Comparative \& Physiological Psychology, 65, 274-281.

KONORSKI, J. (1972). Some ideas concerning physiological mechanisms of so-called internal inhibition. In R. A. Boakes \& M. S. Halliday (Eds.), Inhibition and learning (pp. 341-357). New York: Academic Press.

Malmo, R. B. (1961). Slowing of heart rate following septal selfstimulation in rats. Science, 133, 1128-1130.

MALMo, R. B. (1965). Classical and instrumental conditioning with septal stimulation as reinforcement. Journal of Comparative \& Physiological Psychology, 60, 1-8.

McGowan, B. K., Hankins, W. G., \& Garcia, J. (1972). Limbic lesions and control of the internal and external environment. Behavioral Biology, 7, 841-852.

MCINTIRE, R. W. (1966). Conditioned suppression and self-stimulation. Psychonomic Science, 5, 273-274.

MerriLl, H. K. (1976). Conditioned suppression in rats responding for hypothalamic brain stimulation. Physiological Psychology, 4, 151-154. 
Micco, J. D., \& SCHWARTZ, M. (1971). Effects of hippocampal lesions upon the development of Pavlovian internal inhibition in rats. Journal of Comparative \& Physiological Psychology, 76, 371-377.

Miller, J. J., \& Mogenson, G. J. (1971). Modulatory influences of the septum on lateral hypothalamic self-stimulation in the rat. Experimental Neurology, 33, 671-683.

Morrell, F., HoeppNer, T. J., \& De Toledo-Morrell, L. (1983). Conditioning of single units in visual association cortex: Cell-specific behavior within a small population. Experimental Neurology, 80, 111-146.

MorrIs, R. G. M. (1975). Preconditioning of reinforcing properties to an exteroceptive feedback stimulus. Learning \& Motivation, 6, 289-298.

NADEL, L. (1968). Dorsal and ventral hippocampal lesions and behavior. Physiology \& Behavior, 3, 891-900.

NaUta, W. J. H. (1958). Hippocampal projections and related neural pathways to the midbrain in the cat. Brain, 81, 319-340.

NaUtA, W. J. H. (1982). Neural associations of the limbic system. In A. Beckman (Ed.), The neural basis of behavior (pp. 175-206). New York: Spectrum.

O'KeEFE, J., \& NADEL, L. (1978). The hippocampus as a cognitive map. Oxford: Clarendon Press.

Olds, J., \& Milner, P. (1954). Positive reinforcement produced by electrical stimulation of septal area and other regions of rat brain. Journal of Comparative \& Physiological Psychology, 47, 419-427.

Olton, D. S. (1978). The function of the septo-hippocampal system in spatially organized behavior. In K. Elliot \& J. Whelan (Eds.), Functions of the septo-hippocampal system (pp. 327-342). Ciba symposium 58 (n.s.). Amsterdam: Elsevier.

Perez-Cruet, J., Black, W. C., \& Brady, J. V. (1963). Heart rate: Differential effects of hypothalamic and septal self-stimulation. Science, 140, 1235-1236.

Rawlins, J. N. P., Feldon, J., \& Gray, J. A. (1979). Septohippocampal connections and the hippocampal theta rhythm. Experimental Brain Research, 37, 49-63.

Rescorla, R. A. (1967). Pavlovian conditioning and its proper control procedures. Psychological Review, 74, 71-80.

RESCORLA, R. A. (1969a). Conditioned inhibition of fear resulting from negative CS-US contingencies. Joumal of Comparative \& Physiological Psychology, 67, 504-509.

ResCoRLA, R. A. (1969b). Establishment of a positive reinforcer through contrast with shock. Journal of Comparative \& Physiological Psychology, 67, 260-263.

Rolis, E. T. (1975). The brain and reward. Oxford: Pergamon Press.

Routtenberg, A., \& OlDs, J. (1963). Attenuation of response to an aversive brain stimulus by concurrent rewarding septal stimulation. Federation Proceedings, 22, 515. (Abstract)

RoutTENBERG, A., \& OLDS, J. (1966). Stimulation of dorsal midbrain during septal and hypothalamic self-stimulation. Joumal of Comparative \& Physiological Psychology, 62, 250-255.

Russell, P. J. D. (1975). Conditioned suppression of behavior maintained by intracranial self-stimulation as a function of stimulus intensity. Journal of the Experimental Analysis of Behavior, 23, 277-283.

SEgal, M. (1973). Flow of conditioned responses in the limbic telencephalic system of the rat. Journal of Neurophysiology, 36, 840-854.

Segal, M., Disterhoft, J. F., \& Olds, J. (1972). Hippocampal unit activity during classical aversive and appetitive conditioning. Science, 175, 792-794.

Shibata, K., Katoaka, Y., Y amashita, K., \& Uek1, S. (1986). An important role of the central nucleus and mammillary body in the mediation of conflict in rats. Brain Research, 372, 159-162.

SIEGEL, A., \& SKoG, D. (1970). Effects of electrical stimulation of the septum upon attack behavior elicited from the hypothalamus of the cat. Brain Research, 23, 371-380.

SoubriE, P. (1986). Reconciling the role of central serotonin neurons in human and animal behavior. Behavioral \& Brain Sciences, 9, 319-364.

Sterman, M. B., \& Clemente, C. D. (1962). Forebrain inhibitory mechanisms: Sleep patterns induced by basal forebrain stimulation in the behaving cat. Experimental Neurology, 6, 103-117.

Swanson, L. W., \& Cowan, W. M. (1979). The connections of the septal region of the rat. Journal of Comparative Neurology, 186, 621-656.

Taylor, A. W., Branch, B. J., Cassaday, R. L., \& Turner, B. D. (1973). Septal inhibition of pituitary-adrenal activity in freely behaving rats. Paper presented at the 55th annual meeting of the Endocrine Society, Chicago, II.

Thомаs, E. (1972). Excitatory and inhibitory processes in hypothalamic conditioning. In R. A. Boakes \& M. S. Halliday (Eds.), Inhibition and learning (pp. 359-380). New York: Academic Press.

Thomas, E., \& Evans, G. J. (1983). Septal inhibition of aversive emotional states. Physiology \& Behavior, 31, 673-678.

Thomas, E., \& YADIN, E. (1980). Multiple unit activity in the septum during Pavlovian aversive conditioning: Evidence for an inhibitory role for the septum. Experimental Neurology, 69, 50-60.

Thomas, E., \& YAdIN, E. (1983). Septal unit activity in Pavlovian conditioning: A regional comparison. Society for Neuroscience Abstracts, 9, 518.

Thomas, E., \& YADIN, E. (1987). Neural correlates of conditioning assessed by extracellular unit recording: Implications for neuroplasticity. In N. W. Milgram, C. M. McCleod, \& T. L. Petit (Eds.), Neuroplasticity, learning and memory. New York: Allan R. Liss.

Thompson, R. F. (1976). The search for the engram. American Psychologist, 31, 209-227.

VALENSTEIN, E. S. (1973). Brain control: A critical examination of brain stimulation and psychosurgery. New York: Wiley.

WAGMAN, R. (1972). Septal area modulation of conditioned emotional states in cats. Unpublished master's thesis, Bryn Mawr College, Bryn Mawr, PA.

W AGNer, A. R., \& Rescorla, R. A. (1972). Inhibition in Pavlovian conditioning: Application of a theory. In R. A. Boakes \& M. S. Halliday (Eds.), Inhibition and learning (pp. 301-336). New York: Academic Press.

Weisman, R. G., \& LrTner, J. S. (1972). The role of Pavlovian events in avoidance learning. In R. A. Boakes \& M. S. Halliday (Eds.), Inhibition and learning (pp. 253-270). New York: Academic Press.

Wilkinson, H. A., \& PEELE, T. L. (1963). Intracranial self-stimulation in cats. Journal of Comparative Neurology, 121, 425-440.

Wise, C. D., Berger, B. D., \& STEIN, L. (1972). Benzodiazepines: Anxiety-reducing activity by reduction of serotonin turnover in the brain. Science, 177, 180-183.

YADIN, E., \& THOMAS, E. (1981). Septal correlates of conditioned inhibition and excitation. Journal of Comparative \& Physiological Psychology, 95, 331-340.

Yadin, E., Thomas, E., \& Strickland, C. E. (1987). Effects of anxiolytic agents on conflict behavior in rats with septal or amygdaloid lesions. Society for Neuroscience Abstracts, 13, 454.

Y ADIN, E., Thomas, E., \& VAUGhan, M. P. (1986). Effects of anxiolytic agents on firing of lateral septal units in acute and chronic preparations. Society for Neuroscience Abstracts, 12, 935.

(Manuscript submitted June 1, 1987; revision accepted for publication January 26, 1988.) 